\title{
An insight into risk factors profile of oral cavity and oropharyngeal cancer patients attending two tertiary care hospitals in Jaipur, India
}

\author{
Kopal Sharma*, Lokendra Sharma, Uma Advani, Charu Jain, Alka Bansal, \\ Neha Sharma, Jaya Dadhich
}

Department of Pharmacology, SMS Medical College, Jaipur, Rajasthan, India

Received: 01 December 2018 Accepted: 28 December 2018

\section{*Correspondence to: \\ Dr. Kopal Sharma, Email: sharmakopal85@ gmail.com}

Copyright: (C) the author(s), publisher and licensee Medip Academy. This is an openaccess article distributed under the terms of the Creative Commons Attribution NonCommercial License, which permits unrestricted noncommercial use, distribution, and reproduction in any medium, provided the original work is properly cited.

\begin{abstract}
Background: Oral cancer is the second most prevalent cancers among males in Jaipur city. Assessment of risk factors profile of patients will help the policy makers in initiating new ways to curb the usage of tobacco among masses. The present study aims to find out the risk factors profile of oral and oropharyngeal cancer patients at two hospitals of Jaipur city.

Methods: It was a prospective and observational study. The patients with histologically confirmed diagnosis of oral cavity and oropharyngeal cancers and fulfilling the inclusion criteria were recruited. Data on the demographic profile and clinical information were obtained from hospital and clinical records. The data were analyzed using SPSS version 14 (SPSS Inc., Chicago, IL, USA). Chisquare test was performed to analyse the data.

Results: Out of 400 oral cancer patients included in this study majority of the patients were in the age range of 40-60years and with a significant male preponderance in all the age groups $(\mathrm{P}<0.05)$. The most common habit among males and females was chewing. Buccal mucosa was the most commonly affected site followed by tongue. Both males and females were more likely to be diagnosed in stage 3 ( $\mathrm{p}<0.05)$.

Conclusions: There is a need to reduce the burden of this disease by educating the people about various risk factors which play role in oral cancer development.
\end{abstract}

Keywords: Oral cavity cancers, Oropharyngeal cancers, Risk factors

\section{INTRODUCTION}

Oral cancer is becoming leading health priority in our country, itself accounting for $40 \%$ of all the cancers. ${ }^{1}$ Main etiological factor implicated is tobacco in various forms such as smokeless with betelquid, lime, mawa, acrecanut, mishri, or smoked in form of bidis, hookah, and cigarettes. Other minor etiological factor constitutes HPV, dietary deficiencies, poor oral hygiene. ${ }^{2}$ In the South Asian region over one-third of tobacco consumed is smokeless contributing to $90 \%$ global burden smokeless tobacco. ${ }^{3} \mathrm{By}$ assessing the use of tobacco in the various regions of our country, establishment of effective tobacco control policies could be possible. ${ }^{4}$

Efforts focusing on designing studies targeting specific subset of Indian population at a time to include variations in trends because of locality, affected site, age, sex, type of tobacco consumed are crucial. This will provide our policy makers a common platform for allocation of health budgets and decisions to reduce various tobacco products being used at alarming rate in our country. As the cases of oral cancers are also reported in patients who do not use tobacco it becomes relevant to study the associated risk factor profile of oral cancer patients in Jaipur city where oral cancer is ranked as second prevalent cancer affecting males.

\section{METHODS}

It is a prospective longitudinal study with 400 oral and oropharyngeal cancers patients being treated at SMS 
Medical College and Bhagwan Mahaveer Cancer and Research Centre, Jaipur from May 2017 to December 2018. These centres were chosen as they include both major government and private referral centres in Jaipur city.

\section{Inclusion criteria}

- $\quad$ Patients between 20-70years of age

- And diagnosed histologically with oral and oropharyngeal cancer.

\section{Exclusion criteria}

- Patients with distant metastasis,

- Patients undergoing treatment for their mental disorders, with previous history of mental disorders,

- Co morbidities like brain stroke or other neurological impairment, recurrent tumors,

- HIV infection, hepatitis, still using tobacco, smoking and alcohol,

- Pregnant and lactating mothers.

\section{Sampling}

For sampling two OPD days in a week were selected randomly, to include all the eligible male and female patients on those days, in both the hospitals irrespective of their stage of tumor till desired sample size is achieved. Written informed consent were taken from the volunteered patients and all of them were explained the purpose behind this study and how this study could benefit them. All the recruited patients were followed up to 6 months post treatment. Staging was based on the American Joint Committee on Cancer and included primary tumor size (T), regional neck status (N), and group stage. The site of cancer was classified based on the International Classification of Disease for oncology (ICD-10).

\section{Statistical analysis}

The data were analyzed using SPSS version 14 (SPSS Inc., Chicago, IL, USA). Chi-square test was performed to assess the demographic data. $P$ value of $<0.05$ was considered to be statistically significant while $P$ value $<0.001$ was considered highly significant.

\section{RESULTS}

Out of a total of 400 cases of oral cancer, 234 oral cavity and 166 oropharyngeal cancers patients were reported. Males were found to be significantly $(\mathrm{p}<0.001)$ affected as compared to females. The age group of 41-60 years shows highest incidence of oral cancer among both the males and females (Table 1).

Around $74.8 \%$ males and $49.4 \%$ had one or other associated risk factor habit. The most common habit in males was smoking $(28.7 \%)$ followed by chewing $(25.3 \%)$ while in females the most common associated habit was chewing $(46.3 \%)$. This was followed by combination of chewing, smoking and alcohol in $26.9 \%$ females (Table 2).

Table 1: Prevalence of age with respect to gender.

\begin{tabular}{|llll|}
\hline $\begin{array}{l}\text { Age group } \\
\text { (years) }\end{array}$ & $\begin{array}{l}\text { Gender } \\
\text { Male }\end{array}$ & Female & P value* \\
\hline $21-30$ & 35 & 7 & 0.62 \\
\hline $31-40$ & 67 & 13 & 0.34 \\
\hline $41-50$ & 90 & 14 & $<0.001$ \\
\hline $51-60$ & 95 & 41 & 0.001 \\
\hline $61-70$ & 30 & 8 & 0.96 \\
\hline Total & 317 & 83 & \\
*P value obtained by chi square test \\
\hline
\end{tabular}

Table 2: Prevalence of various habits in relation to gender.

\begin{tabular}{|llll|}
\hline & $\begin{array}{l}\text { Gender } \\
\text { Hale } \\
\mathbf{( 3 1 7 )}\end{array}$ & $\begin{array}{l}\text { Female } \\
(\mathbf{8 3})\end{array}$ & P value \\
\hline Only chewing & 60 & 19 & 0.005 \\
\hline only smoking & 68 & 4 & 0.012 \\
\hline Only alcohol & 12 & 2 & 0.059 \\
\hline $\begin{array}{l}\text { Chewing }+ \\
\text { smoking }\end{array}$ & 24 & 3 & $0.001^{*}$ \\
\hline $\begin{array}{l}\text { Smoking }+ \\
\text { alcohol }\end{array}$ & 10 & 0 & 0.57 \\
\hline $\begin{array}{l}\text { Alcohol + } \\
\text { chewing }\end{array}$ & 19 & 2 & 0.48 \\
\hline $\begin{array}{l}\text { Smoking }+ \\
\text { chewing }+\end{array}$ & 44 & 11 & 0.22 \\
alcohol & 80 & 42 & $<0.0001^{*}$ \\
\hline No habits & & & \\
\hline
\end{tabular}

*P value is highly significant for chewing and smoking habit and in patients with no habits versus in patients with habits

Table 3: Relation between site of cancer within oral cavity and gender.

\begin{tabular}{|llll|}
\hline Site & $\begin{array}{l}\text { Gender } \\
\text { Male } \\
\mathbf{( 3 1 7 )}\end{array}$ & $\begin{array}{l}\text { Female } \\
\mathbf{( 8 3 )}\end{array}$ & \\
\hline Buccal mucosa & 56 & 30 & $0.003^{*}$ \\
\hline Tongue & 57 & 11 & 0.075 \\
\hline Lower alveolus & 35 & 7 & 0.22 \\
\hline Upper alveolus & 8 & 1 & 0.35 \\
\hline $\begin{array}{l}\text { Retromolar } \\
\text { trigone }\end{array}$ & 14 & 4 & 0.86 \\
\hline Hard palate & 3 & 0 & 0.33 \\
\hline Floor of mouth & 5 & 3 & 0.36 \\
\hline Total & 178 & 56 & \\
\hline
\end{tabular}

*P value is significant for buccal mucosa site

The most common sites of cancer in males was tongue, buccal mucosa (32\% and $31.5 \%$, respectively) and in females the most common site being buccal mucosa followed by tongue $(53.5 \%$ and $19.6 \%$, respectively) 
(Table 3). Overall, a significantly higher number of males and females were diagnosed in third stage of cancer $(\mathrm{P}$ $<0.05$ ). Least percentage of patients was diagnosed with stage 1 cancer (Table 4).

Patients without any habits had cancer in buccal mucosa $(6.84 \%)$ and tongue $(6.84 \%)$ followed by retromolar trigone $(3.7 \%)$ more commonly than rest of the sites. Among the patients of tongue cancers the most common habit was chewing (26.47\%), while in buccal mucosa, lower alveolus, hard palate, floor of the mouth cancer patients the most common risk factor were smoking+chewing+alcohol (27.91\%), chewing (23.81\%), smoking+chewing+alcohol (100\%), chewing (50\%) respectively as depicted by Figure 1 .

Table 4: Relation between stage at diagnosis and gender.

\begin{tabular}{|llll|}
\hline Stage & Gender & & P value \\
\hline Stage I & Male (317) & Female (83) & \\
\hline Stage II & 33 & 8 & 0.34 \\
\hline Stage III & 133 & 9 & 0.91 \\
\hline Stage IV & 108 & 20 & $0.03^{*}$ \\
\hline
\end{tabular}

*P value is significant for TNM Stage III patients

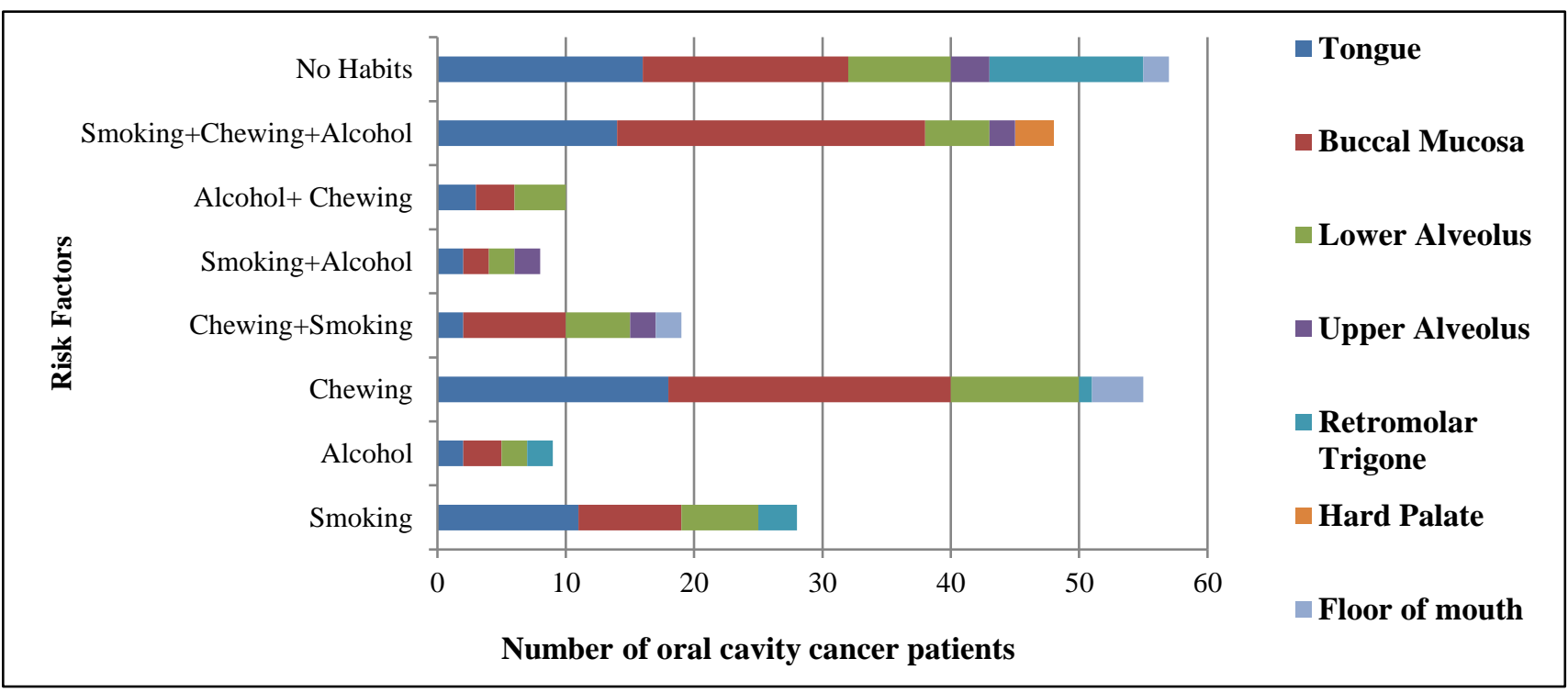

Figure 1: Prevalence of habits in relation to sites for oral cavity cancer patients.

Total $39.16 \%$ of the oropharyngeal cancer patients did not have any associated risk factor.

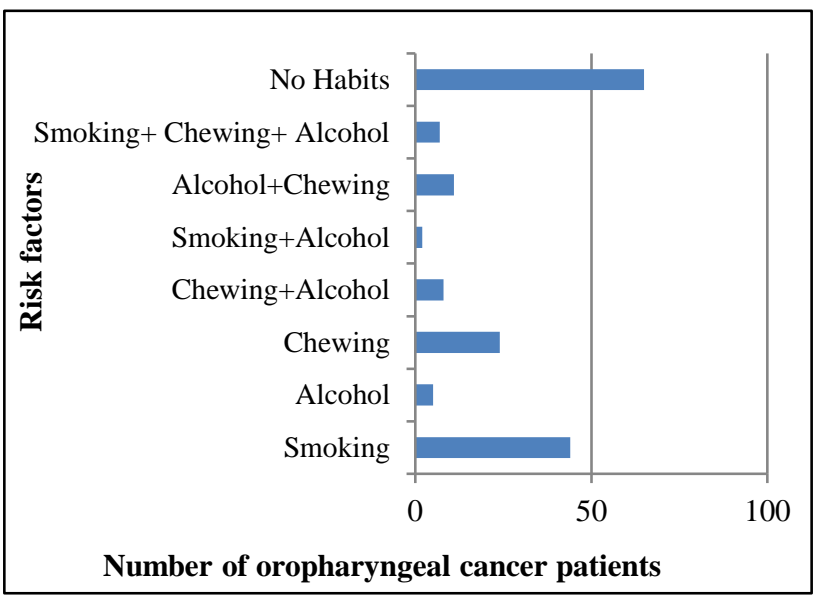

Figure 2: Prevalence of habits in oropharyngeal cancer patients.
Among the various risk factors associated the most common were smoking (26.51\%), chewing (14.46\%) and Alcohol with chewing habits in $6.63 \%$ patients (Figure 2).

\section{DISCUSSION}

This was a prospective and hospital-based study which focused on the oral cancer patients receiving treatment at two tertiary care centers in Jaipur city. Though cancer was thought earlier to be a disease of western world it has significantly affected the residents of developing countries also. There was a male preponderance of cancer occurrence in the present study. This result is congruent with many previous studies..$^{5-7}$

Also, it was noted that among females the preferred way for tobacco consumption was mostly in the form of chewing, while that among males it was mostly smoking followed by chewing and combination of both of these in addition to alcohol consumption. 
In a previous study in Maharashtra it was found that the majority of patients of oral cancers $(41.5 \%)$ were tobacco chewers, followed by patients with other multiple habits such as smoking, alcohol $(28.1 \%) .{ }^{8}$ Knowledge of the type of tobacco consumption behavior in a population has essential health related significance.

Though conventionally oral cavity cancers were thought of as a disease mainly affecting elderly people, but it is revealed in present study that the highest incidence of oral cancers were among middle aged (40-60yrs) males and females. This is in concurrence with some previous studies. ${ }^{9-11}$ But in a previous study depicting cancer statistics in India on the basis of previous registries the pattern observed was different as most of the cases were at very early age of life. ${ }^{7}$

Also, it was found in our study that higher incidence of oral cancers was diagnosed with later stages in both the sexes reflecting the need to improve diagnostic procedures.

Buccal mucosa was the most prevalent site $(36.75 \%)$ depicted in present study in both genders, followed by tongue $(29.06 \%)$ and palate $(1.3 \%)$ being the least common site. This result was in accordance with other studies which stated buccal mucosa as the commonly affected site. The possible reason for this could be the habit of chewing tobacco by majority of the patients $(28.4 \%) .^{9,11,12}$ Tongue was the second most commonly affected site as revealed by the study, the possible reason could be attributed to the habit of smoking, the second highest risk factor in our study $(25.9 \%)$.

Present study reveals that though in majority $(69.5 \%)$ of the patients' risk factors for the development of oral cancers could be identified but in $30.5 \%$ of the patients there were no associated risk factors. The possible reason could be social hindrance among the patients to accept their habit of tobacco consumption or the presence of environmental or other genetic factors in the patients leading to carcinogenesis.

Present study results revealed indulgence of more than half of the study population in one or other risk factors like chewing, smoking, alcohol or their combination. This highlights the need to undertake comprehensive educational campaigns to spread awareness about ill effects of these habits in long term and prevent the burden of this disease.

The inability to include the risk profile of patients of potentially premalignant lesions in our study due to sample size constraint is one drawback of our study.

Future studies should be designed to record the risk factors like tobacco and alcohol and their duration, and frequency. The use of established classification like that of International Classification of Diseases (ICD-10) for cancer coding allows easy comparison with the other populations.

\section{CONCLUSION}

This study highlights the need to spread awareness among the people about ill effects of various forms of tobacco. To reduce the burden of oral cancer better diagnostic procedures should be developed and stringent laws should be implemented by the government against the use of tobacco in our country.

\section{ACKNOWLEDGEMENTS}

Authors would like to thank the Department of Medical Oncology, SMS Medical College and Bhagwan Mahaveer Cancer Hospital for their cooperation.

Funding: No funding sources

Conflict of interest: None declared

Ethical approval: The study was approved by the Institutional Ethics Committee

\section{REFERENCES}

1. Coelho KR. Challenges of the oral cancer burden in India. J Cancer Epidemiol. 2012;2012.

2. Khan Z, Tönnies J, Müller S. Smokeless tobacco and oral cancer in South Asia: a systematic review with meta-analysis. J Cancer Epidemiol. 2014;2014..

3. Siddiqi K, Shah S, Abbas S M, Vidyasagaran A, Jawad M, Dogar O, et al. Global burden of disease due to smokeless tobacco consumption in adults: analysis of data from 113 countries. BMC Med. 2015;13(1):194.

4. Singh A, Ladusingh L. Prevalence and determinants of tobacco use in India: evidence from recent global adult tobacco survey data. PLoS One. 2014;9(12):e114073.

5. Müller S, Pan Y, Li R, Chi AC. Changing trends in oral squamous cell carcinoma with particular reference to young patients: 1971-2006. The Emory University experience. Head Neck Pathol. 2008;2(2): 60-6.

6. Sawlani K, Kumari N, Mishra AK, Agrawal U. Oral cancer prevalence in a tertiary care hospital in India. $\mathbf{J}$ Family Med Community Health. 2014;1(4):1022.

7. Sharma S, Satyanarayana L, Asthana S, Shivalingesh KK, Goutham BS, Ramachandra S. Oral cancer statistics in India on the basis of first report of 29 population-based cancer registries. J Oral Maxillofacial Pathol. 2018 Jan;22(1):18-26.

8. Ajay PR, Ashwinirani SR, Nayak A, Suragimath G, Kamala KA, Sande A, et al. Oral cancer prevalence in Western population of Maharashtra, India, for a period of 5 years. J Oral Res Rev. 2018 Jan 1;10(1):11-4.

9. Sharma P, Saxena S, Aggarwal P. Trends in the epidemiology of oral squamous cell carcinoma in Western UP: an institutional study. Indian J Dent Res. 2010; 21(3):316-9.

10. Addala L, Pentapati CK, Reddy Thavanati PK, Anjaneyulu V, Sadhnani MD. Risk factor profiles of head and neck cancer patients of Andhra Pradesh, India. Indian J Cancer. 2012;49(2):215-9. 
11. Shenoi R, Devrukhkar V, Chaudhuri, Sharma BK, Sapre SB, Chikhale A. Demographic and clinical profile of oral squamous cell carcinoma patients: A retrospective study. Indian J Cancer. 2012;49(1):21-6.

12. Singh MP, Kumar V, Agarwal A, Kumar R, Bhatt ML, Misra S. Clinico-epidemiological study of oral squamous cell carcinoma: A tertiary care centre study in North India. J Oral Biol Craniofac Res. 2016;6(1):31-4.
Cite this article as: Sharma K, Sharma L, Advani U, Jain C, Bansal A, Sharma N, et al. An insight into risk factors profile of oral cavity and oropharyngeal cancer patients attending two tertiary care hospitals in Jaipur, India. Int J Basic Clin Pharmacol 2019;8:275-9. 